\title{
Exceptional Association of a Cerebral Sinus Thrombosis and a Guillain-Barre Syndrome: A New Case Report and Review of the Literature
}

\section{Zakaria Ghoummid', Hassan Ait Bahssain'1, Soukaina Kadiri², Nisserine Louhab ${ }^{2}$, Najib Kissani², Mina Elkhayari ${ }^{1}$, Abdelhamid Hachimi ${ }^{1}{ }^{*}$}

\footnotetext{
${ }^{1}$ Medical ICU, Cadi Ayyad University, Mohammed VI ${ }^{\text {th }}$ University Hospital of Marrakech, Marrakesh, Morocco

${ }^{2}$ Neurology Department, Cadi Ayyad University, Mohammed VI ${ }^{\text {th }}$ University Hospital of Marrakech, Marrakesh, Morocco Email: *abdelhachimi@gmail.com
}

How to cite this paper: Ghoummid, Z., Bahssain, H.A., Kadiri, S., Louhab, N., Kissani, N., Elkhayari, M. and Hachimi, A. (2018) Exceptional Association of a Cerebral Sinus Thrombosis and a Guillain-Barre Syndrome: A New Case Report and Review of the Literature. Case Reports in Clinical Medicine, 7, 391-396.

https://doi.org/10.4236/crcm.2018.76035

Received: May 11, 2018

Accepted: June 12, 2018

Published: June 15, 2018

Copyright $\odot 2018$ by authors and Scientific Research Publishing Inc. This work is licensed under the Creative Commons Attribution International License (CC BY 4.0).

http://creativecommons.org/licenses/by/4.0/

\section{(c) (i) Open Access}

\begin{abstract}
Background: The association of Guillain-Barre syndrome and cerebral sinus thrombosis is uncommon. Case Presentation: We report a 37-year-old patient hospitalized in medical ICU for respiratory distress following a Guillain-Barre syndrome. He had symptomatic treatment in addition to plasma exchange. In the presence of clonic movements, a brain venography magnetic resonance showed a thrombophlebitis of the left lateral sinus, and hence a low-molecular-weight heparin treatment was begun. Immunological, thrombophilia and serological tests were negative. After a favorable evolution, he was transferred to the neurology department. Conclusion: The combination of a Guillain-Barre syndrome and a cerebral sinus thrombosis would suggest a common process. A rigorous investigation, including the use of imaging, is necessary in front of any unusual clinical sign during a GBS.
\end{abstract}

\section{Keywords}

Cerebral Sinus Thrombosis, Guillain-Barre Syndrome, Plasma Exchange, Venography Magnetic Resonance

\section{Introduction}

Although a rare disease ( 5 cases/1,000,000 inhabitants), cerebral sinus thrombosis (CST) is a cause of stroke ( $0.5 \%$ of strokes), characterized by the extreme diversity of their clinical presentation and etiologies [1] with a mortality of less than 5\% during the acute phase [2]. Its etiology and risk factors can be classified as infectious (local, regional or general) and non-infectious affections (general, 
mechanical or hemodynamic, prothrombotic, inflammatory, hematological, medical or unidentified causes) [3]. Guillain-Barre syndrome (GBS) is an immune-mediated disease affecting the peripheral nerves with an inflammatory cell infiltration. GBS has an incidence of 1 - 2 cases/100,000 per year [4] with a mortality of $3 \%-7 \%$ [5], a large spectrum of short-term and long term complications and significant morbidity since $40 \%$ of patients were admitted to the rehabilitation centers [6]. In two-thirds of cases, GBS is a typical case of acute respiratory or gastrointestinal (bacterial or viral) infectious disease [7]. Local or systemic infections are admitted risk factors in the occurrence of CST and GBS; however, no etiological link between the two pathologies has been elucidated [8]. We report an unusual association of CST and GBS in a 37-year-old man and review of published similar cases.

\section{Case Presentation}

The case is a 37-year-old male patient with no past medical history. The patient had been well until four weeks before this admission when untreated gastroenteritis developed. Two weeks later, he presented symmetric lower limbs weakness and tingling which was brusque, bilateral, synchronous and spreading to the arms. On examination, the temperature was afebrile $\left(37.4^{\circ} \mathrm{C}\right)$, the blood pressure $132 / 70 \mathrm{mmHg}$, the pulse 90 beats per minute, the respiratory rate 18 breaths per minute, and the oxygen saturation $98 \%$ while the patient was breathing ambient air. He was conscious (Glasgow Coma Scale was 15) with tetraplegia and hypoglossal nerve palsy. Strength was symmetric and graded as 3 out of 5 in the proximal and distal muscles of the arms, 0 out of 5 in the proximal and distal muscles of the legs. The remainder of the clinical examination (cardiovascular, respiratory and abdominal) was normal. Electromyography (EMG) showed very low motor conduction velocities at the upper limbs and undetectable at the lower limbs with low amplitudes, low sensitivity conduction velocities with very low amplitudes, scattered and elongated $\mathrm{F}$ waves, compatible with acute inflammatory demyelinating polyneuropathy (Guillain-Barre syndrome). Cerebrospinal fluid (CSF) showed increased albumin with normal CSF white blood cell count. Laboratory analysis demonstrated normal blood cell counts (leukocytes $9430 / \mathrm{mm}^{3}$, platelets $305.10^{3} / \mathrm{mm}^{3}$, red cells $4.7 .10^{6} / \mathrm{mm}^{3}$, and hemoglobin 13 $\mathrm{g} / \mathrm{dl}$ ), as was the result of the renal function test (urea $0.3 \mathrm{~g} / \mathrm{l}$, creatinine $6 \mathrm{mg} / \mathrm{l}$ ). The aspartate aminotransferase and alanine aminotransferase were elevated at 70 IU per liter and 353 IU per liter respectively. A cerebral magnetic resonance imaging (MRI, without venography) performed before admission was normal. Plasma exchange was started on the first day of hospitalization in the neurology department. Twenty-four hours later, the patient was referred to our medical ICU because of respiratory distress requiring mechanical ventilation. The patient had symptomatic treatment and treated with plasma exchange. After cessation of sedation, the patient presented clonic movements of the right upper limb and the right side of the face. A cerebral angio-MRI showed a thrombophlebitis of 
the left lateral sinus (Figure 1), hence the initiation of curative anti-coagulation based on low molecular weight heparin associated with sodium valproate. An immunoassay and thrombophilia assessment were normal. Human immunodeficiency virus and hepatitis serologies were negative. After a stay of 23 days in the medical ICU with a good clinical evolution, the patient was transferred to the neurology department. Then, he was discharged from the hospital three weeks later and is alive after a follow-up of 90 days.

\section{Discussion}

The occurrence of CST has been reported as a complication of intravenous immunoglobulin (IVIG) administration in an immune thrombocytopenia purpura [9], a humoral immunodeficiency (Bruton's disease) [10], a polymyositis [11] and an isolated IgG1 deficiency [12]. In the GBS, only one case of CST was published [8]. The latter case was hospitalized for a neurological symptomatology of a headache, dizziness, swallowing disorders, vomiting and unilateral facial and hypoglossal paralysis.

Cerebral thrombosis of the right transverse sinus has been demonstrated on an angio-MRI and an anticoagulant therapy has been initiated. The clinical condition of the patient was worsened by the installation of respiratory distress with paralysis and areflexia of the lower limbs. The diagnosis of GBS has been made in the presence of clinical features, CSF analysis and the EMG findings. Viral serologies were negative.

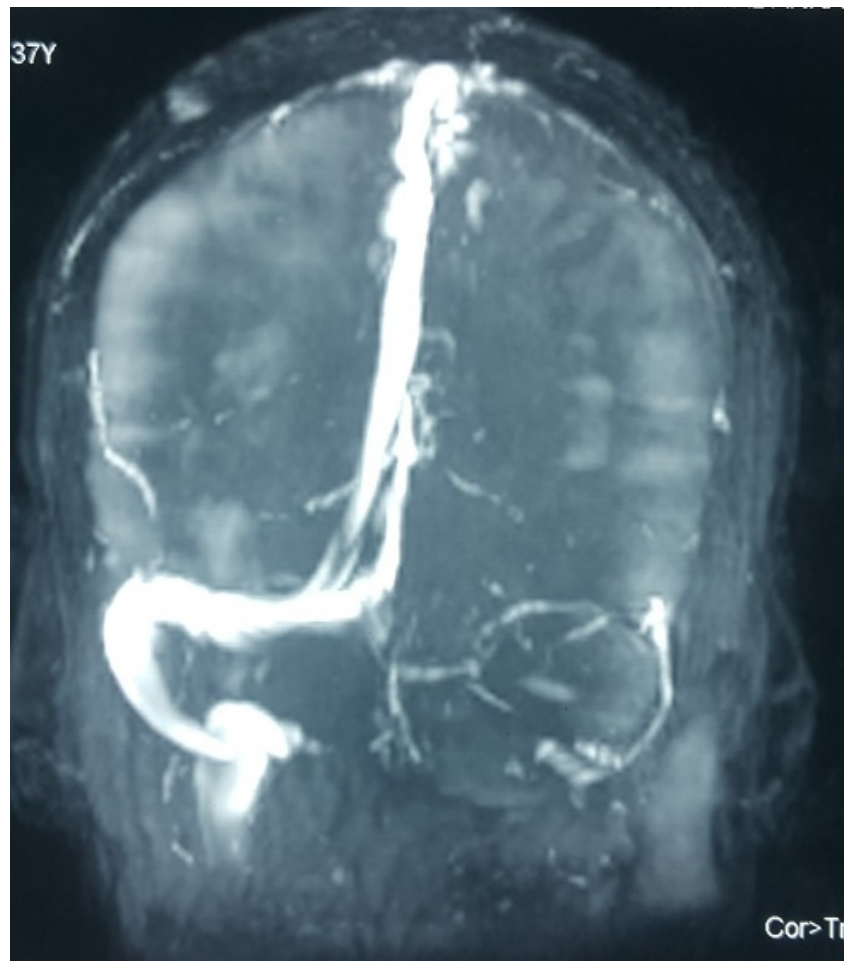

Figure 1. An obstruction of the left lateral sinus on an angio-MRI in a 37-year-old patient hospitalized for Guillain-Barre syndrome. 
While our patient was treated by plasma exchange (PE). However, during 20,485 procedures on the Swedish registry and 144,432 procedures on the Canadian apheresis registry, no CST was reported [13] [14]. Subacutely, CST may occur without or with few nonspecific symptoms in about $30 \%$ of patients [15] [16]. Clinically, our patient had a glosso-pharyngeal nerve palsy, but the initial MRI was normal, although at the beginning (before the 5th day), false negatives could be seen at MRI, an isosignal in T1 and hyposignal in T2, which necessitates the use of sequences $\mathrm{T}^{*}$ and angio-MRI vein for the confirmation of the diagnosis [17]. There is no evidence that CST can cause GBS or vice versa; as a result, this exceptional association may suggest a possible common infectious process that triggers GBS and progresses through the meningeal spaces to the cerebral veins and sinuses to induce CST [8].

\section{Conclusion}

The combination of a GBS and a CST would suggest a common process. A rigorous investigation, including the use of imaging, is necessary in front of any unusual clinical sign during GBS.

\section{Competing Interests}

The authors declare that they have no competing interests.

\section{Informed Consent}

The patient gave informed consent.

\section{Acknowledgements}

The staff at the medical ICU and neurology department.

\section{References}

[1] Bousser, M.G. and Ferro, J.M. (2007) Cerebral Venous Thrombosis: An Update. The Lancet Neurology, 6, 162-170. https://doi.org/10.1016/S1474-4422(07)70029-7

[2] Canhão, P., Ferro, J.M., Lindgren, A.G., Bousser, M.G., Stam, J., Barinagarrementeria, F. and ISCVT Investigators (2005) Causes and Predictors of Death in Cerebral Venous Thrombosis. Stroke, 36, 1720-1725. https://doi.org/10.1161/01.STR.0000173152.84438.1c

[3] Ferro, J.M., Canhao, P., Stam, J., Bousser, M.G. and Barinagarrementeria, F. (2004) Prognosis of Cerebral Vein and Dural Sinus Thrombosis: Results of the International Study on Cerebral Vein and Dural Sinus Thrombosis (ISCVT). Stroke, 35, 664-670. https://doi.org/10.1161/01.STR.0000117571.76197.26

[4] Govoni, V. and Granieri, E. (2001) Epidemiology of the Guillain-Barré Syndrome. Current Opinion in Neurology, 14, 605-613. https://doi.org/10.1097/00019052-200110000-00009

[5] Van den Berg, B., Bunschoten, C., van Doorn, P.A. and Jacobs, B.C. (2013) Mortality in Guillain-Barré Syndrome. Neurology, 80, 1650-1654.

https://doi.org/10.1212/WNL.0b013e3182904fcc 
[6] Bernsen, R.A., de Jager, A.E., Schmitz, P.I. and van der Meché, F.G. (1999) Residual Physical Outcome and Daily Living 3 to 6 Years after Guillain-Barré Syndrome. Neurology, 53, 409-410. https://doi.org/10.1212/WNL.53.2.409

[7] Hahn, A.F. (1998) Guillain-Barré Syndrome. Lancet, 352, 635-641. https://doi.org/10.1016/S0140-6736(97)12308-X

[8] Lagi, A., Spini, S. and Gallori, S. (2009) Cerebral Vein Thrombosis and Guillain-Barre Syndrome: A Challenging Association. American Journal of Emergency Medicine, 27, 758.e3-758.e4. https://doi.org/10.1016/j.ajem.2008.10.029

[9] Al-Riyami, A.Z., Lee, J., Connolly, M. and Shereck, E. (2011) Cerebral Sinus Thrombosis Following IV Immunoglobulin Therapy of Immune Thrombocytopenia Purpura. Pediatric Blood \& Cancer, 57, 157-159. https://doi.org/10.1002/pbc.22968

[10] Barada, W., Muwakkit, S., Hourani, R., Bitar, M. and Mikati, M. (2008) Cerebral Sinus Thrombosis in a Patient with Humoral Immunodeficiency on Intravenous Immunoglobulin Therapy: A Case Report. Neuropediatrics, 39, 131-133. https://doi.org/10.1055/s-2008-1077088

[11] Marie, I., Maurey, G., Hervé, F., Hellot, M.-F. and Levesque, H. (2006) Intravenous Immunoglobulin-Associated Arterial and Venous Thrombosis; Report of a Series and Review of the Literature. British Journal of Dermatology, 155, 714-721. https://doi.org/10.1111/j.1365-2133.2006.07390.x

[12] Evangelou, N., Littlewood, T., Anslow, P. and Chapel, H. (2003) Transverse Sinus Thrombosis and IVIg Treatment: A Case Report and Discussion of Risk-Benefit Assessment for Immunoglobulin Treatment. Journal of Clinical Pathology, 56, 308-309. https://doi.org/10.1136/jcp.56.4.308

[13] Norda, R., Stegmayr, B.G. and Swedish Apheresis Group (2003) Therapeutic Apheresis in Sweden. Transfusion and Apheresis Science, 9, 159-166. https://doi.org/10.1016/S1473-0502(03)00121-6

[14] Rock, G., Clark, B., Sutton, D. and Members of the CAG and CAAN (2003) The Canadian Apheresis Registry. Transfusion and Apheresis Science, 29, 167-177. https://doi.org/10.1016/S1473-0502(03)00111-3

[15] Allroggen, H. and Abbott, R.J. (2000) Cerebral Venous Sinus Thrombosis. Postgraduate Medicine, 76, 12-15. https://doi.org/10.1136/pmj.76.891.12

[16] DeBrujn, S.F., Budde, M. and Teunisse, S. (2001) Clinical Features and Prognostic Factors of Cerebral Venous Sinus Thrombosis in A Prospective Series of $59 \mathrm{~Pa}$ tients. For the Cerebral Venous Sinus Thrombosis Study Group. Journal of Neurology, Neurosurgery, and Psychiatry, 70, 105-108. https://doi.org/10.1136/jnnp.70.1.105

[17] Crassard, I., Ameri, A., Rougemont, D. and Bousser, M.-G. (2012) Thromboses Veineuses Cérébrales. EMC-Neurologie, 9, 1-14 [Article 17-046-R-10]. https://doi.org/10.1016/S0246-0378(12)52829-0 


\section{List of Abbreviations}

GBS: Guillain-Barre Syndrome

CST: Cerebral Sinus Thrombosis

EMG: Electromyography

ICU: Intensive Care Unit

CSF: Cerebrospinal Fluid

MRI: Magnetic Resonance Imaging

IVIG: Intravenous Immunoglobulin

IgG: Immunoglobulin G

PE: Plasma Exchange 